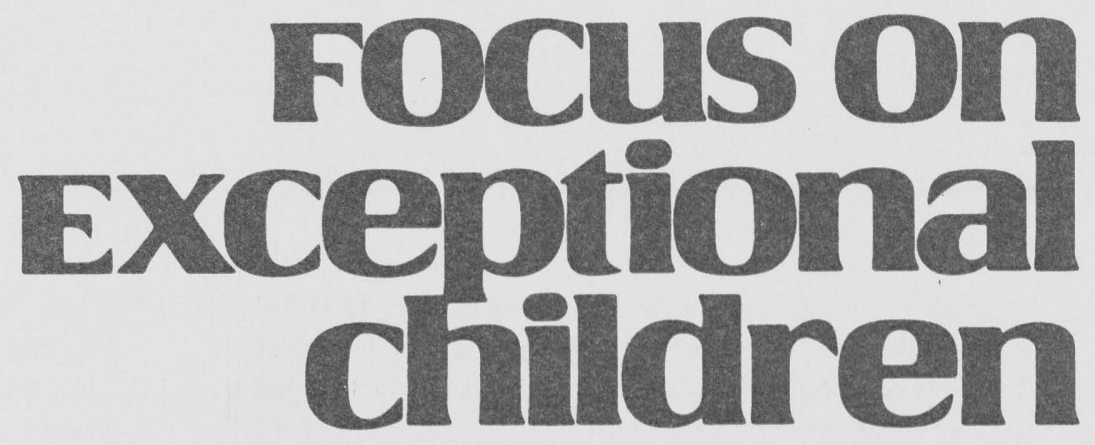

\title{
Classroom Influences on Aggressive and Disruptive Behaviors of Students with Emotional and Behavioral Disorders
}

\author{
Richard E. Shores, Philip L. Gunter, R. Kenton Denny, and Susan L. Jack
}

Of any group of students with defined disabilities, students with emotional and behavioral disorders (EBD) have one of the worst prognoses for successful academic achievement, school completion, and adjustment in adult life (Neel, Meadows, Levine, \& Edgar, 1988; Wagner, D'Amico, Marder, Newman \& Blackorby, 1992). Although a multitude of potential causes exists (cf., Leone, Fitzmartin, Stetson, \& Foster, 1986; Lewis, 1988; Ruhl \& Berlinghoff, 1992), many of the problems associated with children with EBD may be directly related to the aversiveness of the educational environment (Gunter, Denny, Jack, Shores, \& Nelson, 1993; Shores, Gunter, \& Jack, 1993; Sidman, 1989; Skinner, 1989). Students with EBD may engage in unacceptable behavior to escape or avoid the aversiveness of stimuli in schools (Gunter, Denny, et al., 1993; Shores, Gunter, \& Jack, 1993).

Factors such as students' home conditions, drug and alcohol abuse, and peer groups obviously are related to problems in school. Unfortunately, classroom teachers have little direct influence on these factors. Rather, teachers are responsible for assessing the school/classroom environment and using that environment to enrich students' educational programs. Implicit in this responsibility is that teachers develop classrooms that are positively reinforcing to students. This requires awareness of conditions external to the classroom, such as the factors listed above, but, more important, the ability to identify and modify sources of aversive stimulation in the school/classroom environment. The aversiveness of school may contribute to students' aggressive, disruptive, and other antisocial behaviors that often lead to failure in school and contribute to the lack of success in later life (Sidman, 1989; Skinner, 1989).

\section{DEFINITIONS OF AVERSIVE STIMULI}

Aversive stimuli are events or situations that are unpleasant, painful, distasteful, or, in general, events that are disliked. Historically, aversive stimulation in schools has been used to decrease or suppress behavior. When aversive stimuli are applied contingent on responses

Richard Shores, Kenton Denny, and Susan Jack are with the Kansas University Affiliated Programs, Parsons. Philip Gunter is with Valdosta State University in Georgia. 
to decrease or suppress behavior, the tactic of behavior control is known as punishment. Aversive stimulation is effective in suppressing behavior because it also strengthens responses that are successful in escaping the aversive stimulation. Technically, escape behavior is behavior the student has negatively reinforced by behaving in a way that results in the termination of aversive stimuli.

Aversive stimuli also may increase responses that are successful in postponing or preventing the unpleasant stimuli. This is known as avoidance behavior. Escape and avoidance responses are not necessarily detrimental to the student and may even be beneficial. For example, accurately completing an academic task to escape the activity or to avoid failing may be beneficial to the student (Gunter, Denny, et al., 1993). On the other hand, aggressive or disruptive behavior that results in the student's being removed from an activity (escape behavior) or skipping school (avoidance behavior) may inhibit his or her educational progress. Even if the aversive controls are effective in increasing desired behavior (e.g., com-

\section{Focus on
Exceptional
children}

ISSN 0015-511X

FOCUS ON EXCEPTIONAL CHILDREN (USPS 203-360) is published monthly except June, July, and August as a service to teachers, special educators, curriculum specialists, administrators, and those concerned with the special education of exceptional children. This publication is annotated and indexed by the ERIC Clearinghouse on Handicapped and Gifted Children for publication in the monthly Current Index to Journals in Education (CIJE) and the quarterly index, Exceptional Children Education Resources (ECER). It is also available in microfilm from Xerox University Microfilms, Ann Arbor, MI. Subscription rates: Individual, $\$ 30$ per year; institutions, $\$ 40$ per year. Copyright (C) 1993, Love Publishing Company. All rights reserved. Reproduction in whole or part without written permission is prohibited. Printed in the United States of America. Second class postage is paid at Denver, Colorado. POSTMASTER: Send address changes to:

Love Publishing Company

Executive and Editorial Office

1777 South Bellaire Street

Denver, Colorado 80222

Telephone (303) 757-2579

Edward L. Meyen

University of Kansas

Richard J. Whelan

University of Kansas Medical Center
Stanley F. Love Publisher
Glenn A. Vergason Georgia State University

\author{
Holly T. Rumpler \\ Senior Editor
}

pleting the task), the long-term effects of aversive stimuli available in schools may be profoundly detrimental to students' educational progress, as evidenced by the high rates of students' escaping and avoiding school by truancy and exiting school before graduation (Wagner et al., 1992).

In two recent articles, Shores, Gunter, and Jack (1993) and Gunter, Denny, et al. (1993) have expressed concern that typical patterns of classroom management strategies and teaching procedures produce aversive stimulation that most often is unintentional but increases escape and avoidance responses by children (and even teachers). They suggest that current instructional strategies and management techniques may be counterproductive to the successful education of many students.

\section{SOURCES OF AVERSIVE STIMULI}

The potential sources of aversive stimuli in classrooms include those associated with social interactions with teachers and other students, the educational and instructional materials and tasks presented to the students, and inappropriate contingencies of reinforcement. Each of these potential sources of aversive stimulation are discussed, and recommendations regarding their modification, reduction, or elimination are offered. All of these areas and the recommendations are within teachers' control to change.

\section{Social Interactions as Aversive Stimuli}

Over the past several years, we have investigated social interactions in classrooms for children with EBD (e.g., Gunter, Jack, Shores, Carrell, \& Flowers, 1993; Shores, 1993; Shores, Jack, et al., 1993) . Social interaction has been viewed as dyadic exchanges of responses categorized as positive reciprocal interactions or coercive interactions (Patterson \& Reid, 1970). The two types of social exchanges are presented graphically in Figure 1.

Positive reciprocal interactions are described as positive, mutually reinforcing responses emitted by both persons in the exchange. In the positive interaction presented in Figure 1, the student's compliance should be a positive reinforcer for the teacher's mand (telling the student to do something). The teacher's praise, in turn, should positively reinforce the student's compliance. Positive interactions are mutually reinforcing and therefore increase the probability that future social exchanges will be positive.

Coercive interactions occur when one of the interactants emits aversive behavior, possibly to escape the interaction 


\section{POSITIVE INTERACTION}

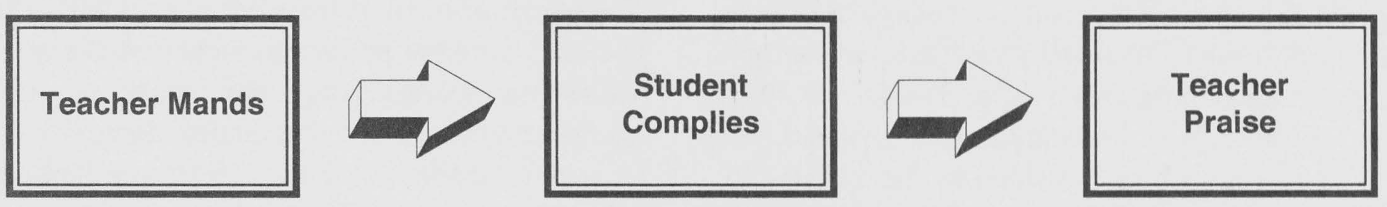

COERCIVE INTERACTION

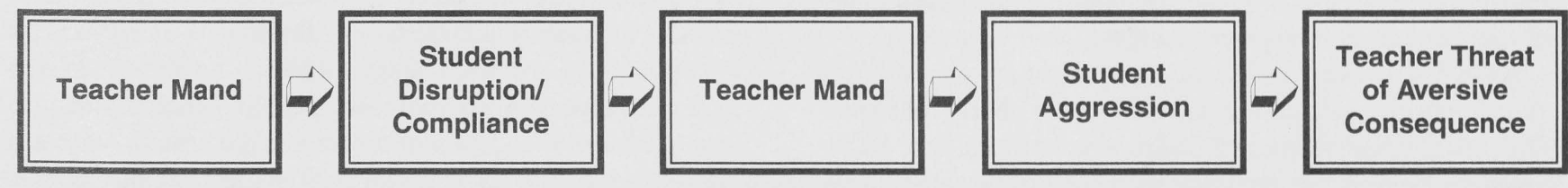

FIGURE 1

Classroom Social Exchanges Illustrating Positive and Coercive Interactions

(negative reinforcement) or to gain something (positive reinforcement). The coercive interaction depicted in Figure 1 reflects an aversive stimulus by the student that ultimately resulted in both interactants' aversive responses. Coercive interactions are likely to be aversive to both parties, which increases the probability of escape from and avoidance of future interactions between those involved. Coercive interactions also may escalate to physical confrontations between the interactants. Strain and Ezzell (1978) found that the physical aggression of students with EBD often began with a teacher telling the student to do something (teacher mand response), followed by student noncompliance, with the interaction escalating to physical confrontation between the two.

In a recent direct observation study of the classroom interactions of students with EBD who had histories of aggressive behavior, Shores, Jack, et al. (1993) recorded who emitted responses, the class of responses, and to whom each person in the streams of interactions directed the responses. The first analyses of these data revealed that both positive and negative responses by teachers were low-rate. Actually, teachers seemed to be passive in their interactions with students. Students with histories of aggressive behavior, however, received six to 20 times more negative consequences from teachers than EBD students considered nonaggressive and non-EBD students. In addition, the researchers observed ex- tremely low rates of positive responses by teachers to all appropriate behaviors by students. Teachers even responded to students' hand-raising, requesting teacher assistance, less than half the time. Students whom the teacher considered aggressive received teacher recognition for their hand-raising less than $20 \%$ of the time.

One of the most important findings from this study was the lack of potentially positive social reinforcement by the teachers. The rates of the groups ranged from one every 2 hours to one every 15 minutes. The most common interaction observed was a teacher mand (telling the student to do something), followed by student compliance, then another teacher mand, teacher talk, or teacher feedback.

In studies completed in the past two years, the low rates of positive responses from teachers has been a consistent finding (Gunter, Denny, et al., 1993; Gunter, Jack, et al., 1993; Gunter, Shores, Jack, \& Denny, 1993; Shores, 1993; Shores, Gunter, \& Jack, 1993; Shores, Jack, et al., 1993). Low rates of teacher social reinforcement logically may increase the aversiveness of the classroom environment. When the schedule of reinforcement is extremely lean (called schedule strain), escape and avoidance responses may occur as if the subject is confronted with aversive stimuli. As Sidman (1989) indicated, withholding reinforcement produces the same effect as using punishment tactics. 
Interactions in classrooms are complex and often extend well beyond a typical "initiation" and "response" exchange. Our ability to identify and reliably measure patterns or streams of interactions has been facilitated by real time microcomputer-based observation programs (Tapp, Wehby, \& Ellis, 1993). In our most recent observations and analyses, sequences of behaviors have been classified by the topography of behavioral events that occur in episodes (Shores, 1993). Sequences have been classified as positive (interactions involving praise or positive consequences and no negative behaviors), negative (interactions involving disruptive, aggressive, negative verbal/gestural, or negative consequences but no positive behaviors), neutral (interactions containing no positive or negative behaviors, e.g., mand>compliance), and mixed (interactions containing both positive and negative behaviors).

Analyses indicated that negative interactions occurred most frequently, accounting for $22 \%$ of the observation time. The typical negative interaction sequence was initiated by the student's engaging in a disruptive response followed by the teacher's giving an instructional mand or talking to the student. The response that ended the interaction most often was another student's disruptive behavior. The next most frequent sequence observed was neutral interaction $(11 \%$ of the observation periods). The most often observed neutral interaction sequence again was the "instructional mand," followed by student compliance and the teacher's giving another mand. Positive interactions, in which one of the interactants engaged in a positive response within the stream of interaction, were extremely low, accounting for only $3 \%$ of the observation periods. The most typical positive interactions were positive statements (praise) by the teacher followed by student talk, or teacher mands followed by student compliance.

Even though the neutral interactions did not contain negative behaviors by either interactant, they may have been coercive for the students with EBD. For example, the absence of positive consequences for the students' compliance may have resulted in the punishing effect mentioned earlier. In addition, the sequence of mand $>$ compliance $>$ mand is not the sequence recommended in the literature on effective instruction. Asking the student to respond in the absence of information with which to respond correctly may be aversive (Gunter, Denny, et al., 1993).

Many teachers clearly do not interact positively with children who have serious behavior problems. Rather, they seem to react to the child's inappropriate behavior. A series of studies was conducted to change the ratio of positive/negative interactions by increasing the teachers' positive responses to targeted students. In the first study (Gunter, Jack, et al., 1993), teacher praise rates were increased on an interval schedule of one every 3 minutes using both differential reinforcement for other behavior (DRO) and differential reinforcement of incompatible behavior (DRI) schedules. When the rate of teacher praise was increased, the rate of the student disruptions decreased; negative interactions with the teachers decreased, and positive interactions increased.

In a related study (Shores, 1993), teachers' use of noncontingent praise was explored. In two classrooms, the teachers were asked to praise the child every 3 minutes no matter what he or she was doing at the time. In one classroom, the teacher failed to praise the child to the criterion level for more than 2 successive days. In the other classroom, the teacher similarly failed to reach the criterion over extensive time; however, she did meet or exceed the 3-minute criterion for 6 consecutive days. During these 6 days, the student engaged in his lowest rate of disruptive behavior. In addition, the rate of positive interactions increased and negative interactions decreased. From the results of the studies presented, enriching the schedule of teachers' positive statements (either contingently or noncontingently) seems to increase the positive interaction between teachers and students and decrease the students' inappropriate classroom behavior.

Although noncontingent praise has been shown to decrease inappropriate behavior in our studies and others (e.g., Vollmer, Iwata, Zarcone, Smith, Mazaleski, 1993), implementing a rich schedule of positive statements using a DRI/ DRO paradigm, or using the adage "Catch the student being good" is probably easier for teachers to implement and maintain over time. Our experience has been that teachers often have a difficult time responding positively to students if the students recently have been engaged in inappropriate behavior. Therefore, we recommend that teachers use the adage, "Catch the student being good" or a more formal schedule (e.g., DRO, DRI) but on a much richer schedule than is typically found in most classrooms. With students who have high rates of disruptive behavior, a rich schedule that results in higher rates of a teacher's positive consequences than student's disruptions is needed (Sprick, 1981). For example, if the student's rate of disruptions is one every 4 minutes, the schedule of praise should be one every 3 to 3.5 minutes.

\section{Instructional Interactions as Aversive Stimuli}

Even though negative teacher behaviors seldom are observed (Shores, Jack, et al., 1993), as indicated earlier, some neutral teacher behaviors may act as aversive stimuli that result in undesired student behaviors. Skinner (1989) and Sidman (1989) have stated that teaching revolves around the 
teacher's prompting the student to engage in a correct response in the presence of instructional stimuli. Prompting students to engage in correct responses should ensure that they can be positively reinforced for accuracy while progressing through the instructional program. Teachers, however, are likely to mand students to engage in activities without ensuring that the student will respond correctly. Even if the students respond to or comply with teachers' mands, teachers rarely provide positive social reinforcement. The teacher is much more likely to follow student compliance with another instructional mand (Shores, Jack, et al., 1993).

The interaction sequence of mand $>$ compliance $>$ mand is considered to be an instructional sequence that is a trial-anderror method (Gunter, Denny, et al., 1993). Trial-and-error instruction may be successful if appropriate feedback and reinforcement are provided. This sequence may be aversive, however, because of the lack of positive reinforcement. When positive reinforcement is absent or occurs infrequently, extinction may result. Behavior during extinction often is similar to that observed when using punishment tactics (Sidman, 1989). That is, students may engage in escape or avoidance behavior in the form of disruptive physical and verbal responses and even aggressive behavior (often defined as "frustration") when they are unsuccessful in correctly performing the response the teacher mands.

One way to ensure that students are successful in responding to teachers' mands is to use a simple instructional sequence advocated by direct instruction (Carnine \& Silbert, 1979; Engelmann \& Carnine, 1982; Silbert, Carnine, \& Stein, 1981) and by effective instruction (Council for Exceptional Children, 1987). Teachers simply provide the information students need to correctly respond to teacher instructional mands. This increases the probability that students will respond correctly and ensures that they will gain positive reinforcement in the presence of the academic materials. Gunter, Shores, Jack, and Denny (1993) observed a decrease in a student's disruptive behavior when the teacher utilized this simple technique of instructional interaction. The results of their study indicated that at least some of the student's disruptive behavior may have been escape behavior resulting from his being unable to respond correctly to the teacher's mands. Preceding the mand with the proper information (even providing the correct response), ensured a correct response.

Does this procedure provide the student with an appropriate escape response (negatively reinforced behavior and, therefore, still an aversive condition), or does it allow the student to perform a response followed by the teacher's positive reinforcement? Analyses of the teacher's positive conse- quences following the student's compliance indicated no substantial change from baseline to intervention conditions. This suggests that the student most likely was given an appropriate means to escape the teacher's mands.

\section{Instructional Materials and Tasks as Aversive Stimuli}

Beyond the potential aversive stimuli available for students with EBD in instructional interactions are those involved with instructional materials and tasks that set the occasion for teacher/student interactions. The difficulty level of the tasks and students' preference (like and dislike) for specific activities are important for this discussion.

\section{Task Difficulty}

The difficulty level of a task is defined by the rate of correct and error responses and the type of errors made during the task (e.g., Deno \& Espin, 1991; Fuchs \& Fuchs, 1986; Stowitschek, Lewis, Shores, \& Ezzell, 1980). A number of studies have demonstrated the students will engage in escape and avoidance behavior if a task is too difficult (e.g., Carr \& Durand, 1985; Carr, Newsom, \& Binkoff, 1980; Sasso, et al., 1992; Weeks \& Gaylord-Ross, 1981). These studies involved students with severe developmental disabilities in analog experimental conditions. The results demonstrated that the students engaged in severe aberrant behavior when confronted with tasks that were beyond their skill level. When the task has a high level of difficulty, students commonly engage in delay responses such as complaining about the task, or more serious disruptive behavior to avoid the task completely. Inappropriate escape behavior also may result from the student's beginning to engage in the task and then disruptive behavior so as to be removed from the task.

Similar to the preceding discussion regarding teachers' instructional interactions with students, difficult tasks often are followed by the student's failure to gain positive reinforcement. Failure to complete difficult tasks also may lead to social stimuli from teachers, parents, and peers that students find aversive. Difficulty of the task may be one of the initial events that increases the intensity of coercive interactions between teachers and students.

Tasks below instructional levels (too easy) also may be aversive to some students (Mayer \& Sulzer-Azaroff, 1991). They may respond with escape behavior (e.g., rushing through the task) or avoiding the task by engaging in behavior to delay or postpone the activity. "Boredom" is the term that typically describes this behavior. 
Teachers also may assign tasks that are too easy, to escape from the students' noncompliance and aggressive and disruptive behaviors related to assignments. In a study by Carr, Taylor, and Robinson (1991), students with problem behaviors were assigned easier tasks than students who were cooperative and compliant to teachers' mands. The authors indicated that the teachers were escaping the aversive stimuli of the students' high rates of noncompliant, disruptive, and aggressive behavior.

The difficulty level of the academic tasks should not be a major problem, as students with disabilities are required to have individual education plans (IEP) derived from appropriate assessment. Unfortunately, research has shown that the student assessment data and the instructional goals often have low correspondence (e.g., Fiedler \& Knight, 1986; Schenck, 1980; Smith \& Simpson, 1989). In addition, the data suggest that errors in developing educational materials and activities are in both directions - too difficult and too easy.

A number of factors probably are associated with assigning inappropriate difficulty levels of academic activities. Most prominent is the lack of appropriate assessment of the students' skill levels. The time of assessment and continuous monitoring of students' progress, as well as the availability of appropriately programmed materials, contribute to the frustration responses of teachers and students alike. Recent development of computerized curriculum-based assessment procedures (Fuchs \& Fuchs, 1986) should allow more accurate assessment and monitoring of students' academic levels. This should increase the effectiveness of educational programming and decrease students' attempts to escape and avoid activities because they are too difficult or too easy. The need remains for appropriately programmed academic materials that have scope and sequence and are programmed to be as errorless as possible. The future of educating not only children who are difficult to teach (i.e., EBD), but all children, requires academic programming that decreases the probability that children will fail.

\section{Preference for Academic Activities}

Preference for an academic activity is demonstrated when the student consistently chooses the specific activity when other activities are available (Gunter, Denny, et al., 1993). The variables that affect preference are not completely understood. Why someone likes one thing and dislikes another probably stems from a number of factors. What is known about preference, however, has emerged from the research on choice responding (e.g., Dattilo \& Rusch, 1985; Durand, Crimmins, Caulfield, \& Taylor, 1989; Neef, Mace, Shea, \& Shade, 1992). The studies on choice demonstrate that choice responding is based on the positive reinforcement available during the experiments or the person's reinforcement history (i.e., positive, negative, or punishment) with the various items and activities available. Activities that are highly preferred seem to develop positive reinforcement value (i.e., high probability behavior) that motivate students to seek out the activity, whereas nonpreferred or rejected activities may assume aversive characteristics that motivate students to escape or avoid the activities.

Dunlap, Kern-Dunlap, Clark, and Robbins (1991) used functional assessment procedures to analyze the motivational effects of several environmental factors, among them a student's preferred academic activities. They reported that the student engaged in fewer disruptive behaviors and had a higher percentage of on-task behavior when given the opportunity to engage in a chosen academic task, as compared to no choice of tasks.

Not all learning and teaching activities will be preferred by all students. Even if the student dislikes the activity (it is nonpreferred), the student may have to engage in the activity for the benefit of his or her educational future. Students cannot be allowed to engage in only preferred activities to decrease inappropriate escape or avoidance responses. The aversiveness of nonpreferred activities, however, may be modified by increasing the positive reinforcement for choosing the nonpreferred activity. The data on preference suggest that even low-preferred activities need not be aversive if strong positive reinforcement systems are offered (e.g., Neef et al., 1992).

\section{Classroom Management Strategies as Aversive Stimuli}

General classroom management strategies provide structure to the classroom that aids in controlling students' behavior. Shores, Gunter, and Jack (1993) have argued that these systems have little direct control of students' behavior but, instead, serve as setting events for the more direct control that teacher/student interactions provide. Setting events have weak direct effects but may serve to increase the positive or coercive impact of teachers' interactions with students (Brown, Bryson-Brackmann, \& Fox, 1986; Wahler \& Fox, 1981).

Shores, Gunter, and Jack (1993) reviewed four systems recommended by several major texts on methods of teaching children and youth with serious emotional and behavioral disorders (e.g., Kerr \& Nelson, 1983; Morgan \& Jenson, 1988; Paine, Radicchi, Rosellini, Deuchman, \& Darch, 1983). The strategies reviewed were: physical organization of the classroom, teacher movement patterns, classroom rules, and classroom reinforcement systems such as token or point systems. 
All of these general strategies are empirically documented as effective in aiding teachers' management of deviant classroom behavior.

\section{Classroom Arrangement}

For many years special education textbooks have suggested specific arrangements of the physical structure of classrooms to aid in controlling student behavior (Haring \& Phillips, 1962; Hewett, 1968; Strauss \& Lehtinen, 1947). Although the early researchers disagreed on the theoretical rationale for the classroom arrangements, they agreed on several specific ideas regarding the arrangement. For example, they agreed that the room should contain independent work areas such as a study cubicle, have a group instruction area, and be neat. More recent research has supported some of these notions. For example, space between students has been shown to affect disruptive behavior, in that greater space (or being in study cubicles) seems to decrease interactions between students and may increase the interactions with the teacher (Haubrich \& Shores, 1976; Shores \& Haubrich, 1969).

Recent research by Gunter, Shores, Jack, Denny, and DeBriere (1993) supports and extends earlier findings in that, even in regular classrooms, students need space between them to decrease student interactions and increase attention to task. They observed more academic engagement of a student with multiple behavior problems in an integrated classroom when desks were arranged in rows rather than in learning clusters containing four students. In most classrooms, this means that students should be seated in rows for independent and large-group instruction but have learning centers to allow peer interactions and small-group instruction.

\section{Teacher Movement Patterns}

Teachers' movement patterns are related to the physical arrangement of the classroom. Several authors have recommended that teachers establish a movement pattern while instructing the class (e.g., Good \& Brophy, 1987; Paine et al., 1983). Fifer (1986) found that more movement by teachers decreased inappropriate student behavior and increased positive interactions between teachers and students. Gunter, Shores, Jack, Rasmussen, and Flowers (in press) found that increasing the time a teacher was away from her desk during independent activities resulted in increased student academic engagement. In addition, those authors found that, when the teacher was prompted to praise a student who had a history of aggressive behavior, the praise statements far exceeded the level prompted when the teacher was in closer proximity to the student. When not in proximity, the teacher praised only when prompted.
Teacher movement around the classroom allows him or her to be in closer proximity to more of the students than if the teacher remains at a desk. If the teacher is in proximity to students, he or she is more likely to respond to the students. Proximity of teachers to students has been shown to increase the power of both positive social reinforcement (e.g., Broden, Bruce, Mitchell, Carter, \& Hall, 1970; Hall, Lund, \& Jackson, 1968) and social punishers (e.g., Van Houten, Nau, MacKenzie-Keating, Sameoto, \& Colavecchia, 1982). From the literature reported, teachers' movements in classrooms clearly affect student behavior, as well as their own responses to students.

\section{Classroom Rules}

Classroom and school-wide rules clearly define the expectations of students' behaviors and clarify the consequences of those behaviors. Rules alone do not control behavior but seem to increase the power of praise (e.g., Madsen, Becker, \& Thomas, 1968; O'Leary, Becker, Evans, \& Saudargas, 1969) and token reinforcement systems (e.g., Greenwood, Hops, Delquadri, \& Guild, 1974).

Criteria for effective development of rules are:

1. Establish only four or five rules.

2. State rules positively rather than negatively (i.e., describe what a student should do instead of shouldn't do).

3. Define rules as observable behavior, using as little inference as possible in observing.

4. Provide definitions of the positive consequences to be presented for following rules and negative consequences for breaking rules.

5. Allow students to participate in developing the rules.

6. Post rules so all students can see them.

7. Review rules and consequences (including examples and non-examples) as often as needed to ensure that students know the rules and the consequences (both positive and negative).

\section{Token Economy and Reinforcement Systems}

Token economy systems have a long history in educational programs for students with disabilities. Over the years the programs using token economy systems have proven to be highly successful in promoting positive outcomes for EBD students (cf., Kerr \& Nelson, 1983). These programs have in common the use of events (e.g., tokens, points, checks), given to students for engaging in specific behaviors; these then are exchangeable for a variety of other events or items (e.g., freetime, access to computer games, candy). Guidelines for the development and use of token systems are: 
1. Assign a value to each event (i.e., potential reinforcers such as points, tokens, checks). The events should be exchangeable for other items or activities (back-up reinforcers).

2. Clearly define contingencies (i.e., the relationship of giving potential reinforcers [events] for specific student behavior). In doing so, the students clearly understand how many tasks they must complete or how long they must work on a task to receive events (token reinforcers).

3. Make back-up reinforcers available frequently (e.g., daily), at least in the early stage of implementing the system.

4. Carefully monitor student behaviors daily to determine the effectiveness of the reinforcement system.

Token economies represent a formalized and systematic attempt for delivery of reinforcers. Less structured approaches, too, are present in many classrooms for EBD students.

\section{ANALYSIS OF TEACHERS' USE OF BEHAVIOR MANAGEMENT STRATEGIES}

Subsequent to the review presented above, Shores (1993) interviewed 20 classroom teachers of EBD children regarding their use of behavior management strategies. The interviewees consisted of 13 regular education teachers in fullinclusion programs and seven teachers in special education classrooms for children with EBD. The interviewer questioned the teachers' use of classroom organization, their movement patterns, their classroom rules, and their reinforcement and punishment systems.

The results regarding classroom organization plans revealed that few teachers utilized a classroom organization strategy. In the integrated classrooms, the rooms were too small for the number of students to have individual study areas other than their desks. Because the room was small, distance between students was slight. Many classrooms utilized the row seating arrangement, but few had organized learning centers. In other classrooms the seating arrangement consisted of several students facing each other at long tables or in clusters of desks. In self-contained classrooms a few of the teachers used study cubicles, and most had small-group instructional areas.

In no case did the teacher have a planned pattern of moving around the classroom. Many of the teachers reported that they used proximity control when a student was being "difficult." Often this took the form of moving the student nearer to the teacher or the paraprofessional.

In the interview approximately half of the teachers reported that they developed rules that met most of the criteria recommended above. Of those who had rules stated positively ("to do" statements), few had stated consequences for following rules. All but one classroom had consequences for violating the rules.

Reinforcement systems that were used were often tied to the classroom rules and were the same for everyone in the class. Often the contingencies for earning points were "all or nothing" over an extended time (usually one week). For example, a student's contingency for earning a back-up reinforcer was to earn $\mathrm{X}$ number of points per day during one week. If the points were not earned one day, a student could not gain the back-up reinforcer at the end of the week. The back-up reinforcers often were activities in which all students participated, such as popcorn parties, baking cookies, or going on field trips. The students seldom had a choice of backup reinforcers.

Another type of aversive controls observed were systems in which points or tokens were removed when a child violated the rules or were never given for engaging in specified appropriate behavior or following the rules. Often the tokens or points were given or removed contingent on the teacher's subjective judgment and not on students' behaviors.

Nearly all of the teachers reported that they learned about their classroom management strategies from other teachers or based them on their own experiences. Only one teacher reported learning about the system used from a teacher education program.

\section{SUMMARY}

We need to identify sources of aversive stimuli that may be present in many classrooms. Interactions between students and teachers, academic activities offered, and classroom management strategies utilized to control undesirable student behaviors are potential areas in which to begin this process. Based on our own studies and others reviewed here, teachers clearly do rely on aversive procedures, both unintentionally and intentionally, to control undesirable behaviors. Our concern has been the unintentional and unrecognized use of aversive stimuli that increase student escape and avoidance responses, which may be detrimental to their education and contribute to their developing and maintaining behavior disorders. Obviously, a great deal of research is needed to empirically identify sources of aversive stimuli in school environments, to clarify the relationship of the stimuli to students' behaviors, and to develop procedures that decrease the resulting escape and avoidance responses.

Because the research base is limited, the recommendations we present here should be accepted with caution. A summary of these suggestions is: 
1. Use classroom management strategies to increase the opportunity to be positive with the students.

2. Use classroom organization and teacher (and paraprofessional) classroom movement about the classroom to aid in providing instruction or bringing classroom behavior under the control of the academic stimuli.

3. Adapt the reinforcement systems to the individual's behavior. Group reinforcement time is not the only way to organize the system. Look carefully at the contingencies for each student.

4. Monitor student performance. If the student is making errors, refusing to participate, or engaging in disruptive and aggressive behavior, attempt to locate the source of aversiveness in the classroom and modify it.

5. Try to allow the students to enjoy and gain positive reinforcement for learning academic and appropriate social skills.

Many of our suggestions are based on instructional practices that have been referred to as direct instruction, effective instruction, precision teaching, and general guidelines for classroom management. Each of these well-developed programs shares the overall recognition that instruction should be planned and systematic. In addition, each recognizes the importance of positive reinforcement in the design of instructional programs. We believe the direction for addressing coercive classroom interactions and escape/avoidance-motivated disruptive and aggressive behavior should come from effective instructional practices.

\section{REFERENCES}

Brown, W., Bryson-Brackmann, B., \& Fox, J. (1986). The usefulness of J.R. Kantor's setting event concept for research on children's social behavior. Child \& Family Behavior Therapy, 8(2), 15-25.

Broden, M., Bruce, C., Mitchell, M. A., Carter, V., \& Hall, R. V. (1970). Effects of teacher attention on attending behavior of two boys at adjacent desks. Journal of Applied Behavior Analysis, 3, 199-203.

Carnine, D., \& Silbert, J. (1979). Direct instruction reading. Columbus, OH: Merrill Publishing.

Carr, E. G., \& Durand, M. V. (1985). Reducing behavior problems through functional communication training. Journal of Applied Behavior Analysis, 18, 111-126.

Carr, E. G., Newsom, C. D., \& Binkoff, J. A. (1980). Escape as a factor in the aggressive behavior of two retarded children. Journal of Applied Behavior Analysis, 13, 101-117.

Carr, E. G., Taylor, J. C., \& Robinson, S. (1991). The effects of severe behavior problems in children on the teaching behavior of adults. Journal of Applied Behavior Analysis, 24, 523-535.

Council for Exceptional Children. (1987). Academy for effective instruction: Working with mildly handicapped students. Reston, VA: Author.

Dattilo, J., \& Rusch, F. R. (1985). Effects of choice on leisure participation for persons with severe handicaps. Journal of the Association for Persons with Severe Handicaps, 10, 194-199.
Deno, S. L., \& Espin, C. A. (1991). Evaluation strategies for preventing remediating basic skill deficits. In G. Stoner, M. R. Shinn, \& H. M. Walker (Eds.), Interventions for achievement and behavior problems (pp. 269-287). Silver Spring, MD: National Association of School Psychologists.

Dunlap, G., Kern-Dunlap, L., Clark, S., \& Robbins, F. R. (1991). Functional assessment, curricular revision, and severe behavior problems. Journal of Applied Behavior Analysis, 24(2), 387-397.

Durand, V. M., Crimmins, D. B., Caulfield, M., \& Taylor, J. (1989). Reinforcer assessment: I. Using problem behavior to select reinforcers. Journal of the Association for Persons with Severe Handicaps, 14, 113-126.

Engelmann, S., \& Carnine, D. (1982). Theory of instruction: Principles and applications. New York: Irvington Publishers.

Fiedler, J. F., \& Knight, R. R. (1986). Congruence between assessed needs and IEP goals of identified behaviorally disabled students. Behavioral Disorders, 12, 22-27.

Fifer, F. L. (1986). Effective classroom management. Academic Therapy, 21(4), 401-410.

Fuchs, L. S., \& Fuchs, D. (1986). Effects of systematic formative evaluation on student achievement. Exceptional Children, 53, 199-208.

Good, T. L., \& Brophy, J. E. (1987). Looking in classrooms. New York: Harper \& Row

Greenwood, C., Hops, H., Delquadri, J., \& Guild, J. (1974). Group contingencies for group consequences in classroom management: A further analysis. Journal of Applied Behavior Analysis, 7, 413-425.

Gunter, P. L., Denny, R. K., Jack, S. L., Shores, R. E., \& Nelson, C. M. (1993). Aversive stimuli in academic interactions between students with serious emotional disturbance and their teachers. Behavioral Disorders, 18, 265-274.

Gunter, P. L., Jack, S. L., Shores, R. E., Carrell, D., \& Flowers, J. (1993). Lag sequential analysis as a tool for functional analysis of student disruptive behavior in classrooms. Journal of Emotional and Behavioral Disorders, 1, 138-148.

Gunter, P. L., Shores, R. E., Jack, S. L., \& Denny, R. K. (1993). A case study of the effects of aversive stimuli in instructional interactions on the disruptive behaviors of a child identified with severe behavior disorders. Manuscript submitted for publication.

Gunter, P. L., Shores, R. E., Jack, S. L., Denny, R. K., \& DeBriere, T. (1993). An investigation of the effects of teacher/student proximity on the academic engagement and disruptive behaviors of two children with severe behavior disorders. Manuscript in preparation.

Gunter, P. L., Shores, R. E., Jack, S. L., Rasmussen, S., \& Flowers, J. (in press) Teacher/student proximity: A strategy for classroom control through teacher movement. Teaching Exceptional Children.

Hall, R. V., Lund, D., \& Jackson, D. (1968). Effects of teacher attention on study behavior. Journal of Applied Behavior Analysis, 16(2), 243-249.

Haring, N., \& Phillips, E. (1962). Educating emotionally disturbed children. New York: McGraw-Hill.

Haubrich, P. A., \& Shores, R. E. (1976). Attending behavior and academic performance of emotionally disturbed children. Exceptional Children, $42,337-338$.

Hewett, F. (1968). The emotionally disturbed child in the classroom. Boston: Allyn \& Bacon.

Kerr, M. M., \& Nelson, C. M. (1983). Strategies for managing behavior problems in the classroom. Columbus, $\mathrm{OH}$ : Merrill Publishing.

Leone, P. E., Fitzmartin, R., Stetson, F., \& Foster, J. (1986). A retrospective follow-up of behaviorally disordered adolescents: Identifying predictors of treatment outcome. Behavioral Disorders, 11, 87-97.

Lewis, W. W. (1988). The role of ecological variables in residential treatment. Behavioral Disorders, 13, 98-107. 
Madsen, C., Becker, W., \& Thomas, D. (1968). Rules, praise, and ignoring: Elements of elementary classroom control. Journal of Applied Behavior Analysis, 1, 139-150.

Mayer, G. R., \& Sulzer-Azaroff, B. (1991). Interventions for vandalism. In G. Stoner, M. R. Shinn, \& H. M. Walker (Eds.), Interventions for achievement and behavior problems (pp. 559-580). Silver Spring, MD: National Association of School Psychologists.

Morgan, D., \& Jenson, W. (1988). Teaching behaviorally disordered students: Preferred practices. Columbus, $\mathrm{OH}$ : Merrill Publishing.

Neef, N. A., Mace, C., Shea, M. C., \& Shade, D. (1992). Effects of reinforcer rate and reinforcer quality on time allocation: Extensions of matching theory to educational settings. Journal of Applied Behavior Analysis, 25, 691-699.

Neel, R. S., Meadows, N., Levine, P., \& Edgar, E. B. (1988). What happens after special education: A statewide follow-up study of secondary students who have behavioral disorders. Behavioral Disorders, 13, 209-216.

O’Leary, K., Becker, W., Evans, M., \& Saudargas, R. (1969). A token reinforcement program in a public school: A replication and systematic analysis. Journal of Applied Behavior Analysis, 2, 3-13.

Paine, S. C., Radicchi, J., Rosellini, L. D., Deuchman, L., \& Darch, C. B. (1983). Structuring your classroom for academic success. Champaign, IL: Research Press.

Patterson, G. R., \& Reid, J. B. (1970). Reciprocity and Coercion: Two facets of social systems. In C. Neuringer \& J. L. Michael (Eds.), Behavior modification in clinical psychology (pp. 133-177). New York: Appleton.

Ruhl, K. L., \& Berlinghoff, D. H. (1992). Research on improving behaviorally disordered students' academic performance: A review of the literature. Behavioral Disorders, 17, 178-190.

Sasso, G. M., Reimers, T. M., Cooper, L. J., Wacker, D., Berg, W., Steege, M., Kelly, L., \& Allaire, A. (1992). Use of descriptive and experimental analyses to identify the functional properties of aberrant behavior in school settings. Journal of Applied Behavior Analysis, 25(4), 809-821.

Schenck, S. (1980). The diagnostic/instructional links in individualized education programs. Journal of Special Education, 14, 337-345.

Shores, R. E. (1993, April). General classroom management strategies: Are they effective with violent and aggressive students? Paper presented at Council for Exceptional Children Annual Convention, San Antonio, TX.

Shores, R. E., Gunter, P. L., \& Jack, S. L. (1993). Classroom management strategies: Are they setting events for coercion? Behavioral Disorders, 18(2), 92-102.

Shores, R. E., \& Haubrick, P. A. (1969). Effects of cubicles in educating emotionally disturbed children. Exceptional Children, 36, 21-24.

Shores, R. E., Jack, S. L., Gunter, P. L., Ellis, D. N., DeBriere, T., \& Wehby, J. (1993). Classroom interactions of children with severe behavior disorders. Journal of Emotional \& Behavioral Disorders, 1, 27-39.
Sidman, M. (1989). Coercion and its fallout. Boston: Authors Cooperative, Inc.

Silbert, J., Carnine, D., \& Stein, M. (1981). Direct instruction mathematics. Columbus: OH: Merrill Publishing.

Skinner, B. F. (1989). Recent issues in the analysis of behavior. Columbus, $\mathrm{OH}$ : Merrill Publishing.

Smith, S. W., \& Simpson, R. L. (1989). An analysis of individualized education programs (IEPs) for students with behavioral disorders. Behavioral Disorders, 14, 107-116.

Sprick, R. (1981). The solution book: A guide to classroom discipline. Chicago: Science Research Associates.

Strain, P. S., \& Ezzell, D. (1978). The sequence and distribution of behavioral disordered adolescents' disruptive/inappropriate behaviors. Behavior Modification, 2, 403-425.

Stowitschek, C. E., Lewis, B. L., Shores, R. E., \& Ezzell, D.L. (1980). Procedures for analyzing student performance data to generate hypotheses for the purpose of educational decision making. Behavioral Disorders, 5, 136-150.

Strauss, A. A., \& Lehtinen, L. E. (1947). Psychopathology and education of brain injured children: Vol 1. New York: Grune and Statton.

Tapp, J. T., Wehby, J. H., \& Ellis, D. N. (1993). A multiple option observation system for experimental studies: MOOSES. Unpublished manuscript, Vanderbilt University.

Van Houten, R., Nau, P. A., MacKenzie-Keating, S. E., Sameoto, D., \& Colavecchia, B. (1982). An analysis of some variables influencing the effectiveness of reprimands. Journal of Applied Behavior Analysis, $15,65-83$.

Vollmer, T. R., Iwata, B. A., Zarcone, J. R., Smith, R. G., \& Mazaleski, J. L. (1993). The role of attention in the treatment of attention-maintained self-injurious behavior: Noncontingent reinforcement and differential reinforcement of other behavior. Journal of Applied Behavior Analysis, 26, 9-21.

Wagner, M., D’Amico, R., Marder, C., Newman, L., \& Blackorby, J. (1992). What happens next? Trends in the post school outcomes of youth with disabilities. Menlo Park, CA: SRI.

Wahler, R., \& Fox, J. (1981). Setting events in applied behavioral analysis: Toward a conceptual and methodological expansion. Journal of Applied Behavior Analysis, 14, 327-338.

Weeks, M., \& Gaylord-Ross, R. (1981). Task difficulty and aberrant behavior in severely handicapped students. Journal of Applied Behavior Analysis, 14, 449-463.

Preparation of this manuscript was partially supported by grants HO23C00127-92 and HO23C20138 from the Department of Education, Office of Special Education. 


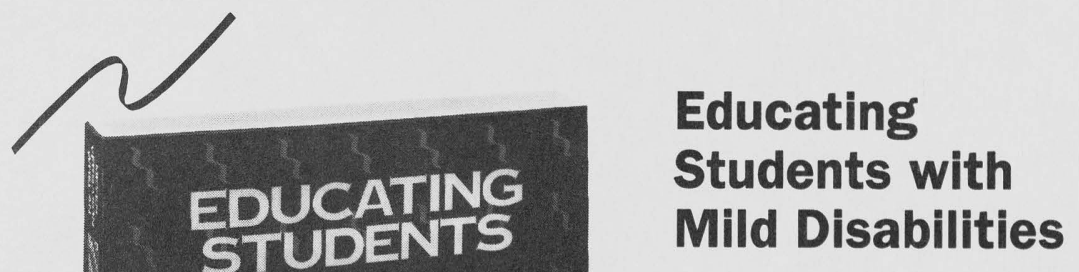

WITH

MILD

DISABILITIES

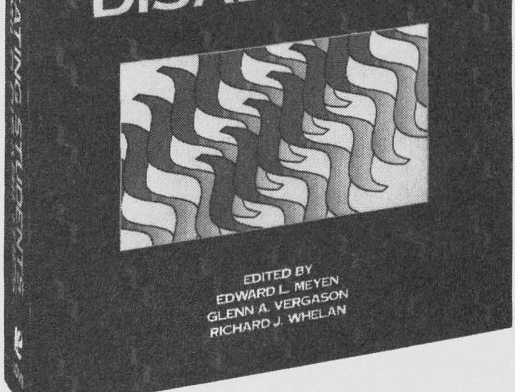

ISBN 0-89108-230-1

paperback / 29.95

\section{Edited by}

Edward L. Meyen,

University of Kansas

Glenn A. Vergason,

Georgia State University

Richard J. Whelan,

University of Kansas

This new book is a collection of contemporary essays dealing with perspectives and practices. It explores the developments that are forming the foundation of special education and related services to students with mild disabilities.

\section{Challenges Facing Special Education}

Edited by

Edward L. Meyen, University of Kansas

Glenn A. Vergason, Georgia State University

Richard J. Whelan, University of Kansas
This unique book addresses the critical issues and challenges in special education. The authors examine, in depth, the major trends and relate these to the latest research findings. Special education is changing and educational reform is happening. This book will stimulate discussion and critical
It includes the latest practices linking assessment and curriculum Whole language, reading, math, and collaboration are all examined. Each chapter provides practitioners and teacher educators with the best practices and procedures. Brightly written and up-to-date, it is perfect for courses dealing with learning disabilities, educable mental retardation, behavior disorders, and other mild disabilities.

Special Features

- Provides background and guidelines for an effective and quality curriculum

- Focuses on specific practices and methods

- Translates the latest research into best practices

- Strategies and in-depth examination of major issues

\section{Free Appropriate Public Education}

\section{The Law and Children with Disabilities, Fourth Edition}

H. Rutherford Turnbull, III, University of Kansas
This definitive resource covers legislation, case law techniques, statutory techniques, due process, parent participation, and more. The work includes materials on AIDS and the Timothy $W$. case. You will find the latest information on the Americans with Disabilities Act and the amendments to the Individual thinking. It is up-to-date on all the issues in the field.

Some of the topics covered include collaboration, early childhood, ADD, health care, severe disabilities, disadvantaged gifted, curriculum-based measurement, school reform, inclusion, and much, much more. with Disabilities Education Act. It includes far-reaching implications for both children with special needs and the schools who have the responsibility to educate them. The new edition includes all of the legal action through mid-1992. It is new, accurate, and up-to-date.

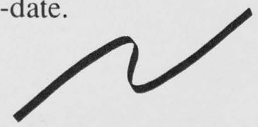

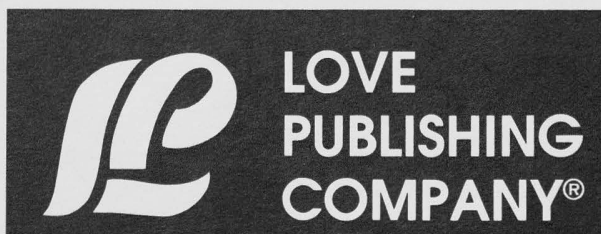




\section{Professional \\ update}

\section{November 3-7, 1993}

National Association for Gifted Children

Westin Peachtree Hotel

Atlanta, GA

Contact: NAGC, (202) 785-4268

\section{November 4-6, 1993}

Association for Persons with Severe Handicaps

Hilton Hotel and Towers

Chicago, IL

Contact: TASH, (206) 361-8870

\section{November 18-21, 1993}

American Speech-Language-Hearing Association Anaheim Convention Center

Anaheim, CA

Contact: ASHA, (301) 897-5700

\section{December 12-14, 1993}

Division for Early Childhood-CEC

International Early Childhood Conference

San Diego Marriott Hotel

San Diego, CA

Contact: CEC, (703) 620-3660

\section{PERMISSIONS AND COPYRIGHT}

All rights are reserved. No part of this publication may be reproduced, photocopied, faxed, stored in a retrieval system, or transmitted, in any form or by any means, electronic, mechanical, recording or otherwise, without the prior written permission of the publisher.
Back issues are available for sale. Reproduction requires permission and payment of fees. It is illegal and a violation of Federal copyright law to reproduce this publication without permission. Direct all inquiries to the permissions editor. 